24. Patel LP, Cohen T. New Perspectives on error in critical care. Cur Opin Crit Care. 2008. 14:456-459

Stone R, McCloy R. Ergonomics in Medicine and Surgery. BMJ. 2004. 328:1115-8

26. Schlachta CM, Sorsdahl AK, Lefebvre KL, McCune ML, Jayaraman S. A model for longitudinal mentoring and telementoring of laparoscopic colon surgery. Surgical Endoscopy. 2009. 23:1634-1638.

27. Foale CM, Kaleri AY, Sargsyan AE, Hamilton DR, Melton S, Martin D, Dulchavsky SA. Diagnostic Instrumentation Aboard ISS: Just-In-Time Training for Non-Physician Crewmembers. Aviat Space Environ Med. 2005. June, 76(6):

Gregory E Stewart (BMSc MD CCFP(c)) completed medical school at The University of Ottawa and is now a resident at The University of Western Ontario in the Rural Family Medicine Program in Goderich. As a pilot and traveler as well as a physician in training, he investigated "Medical Education for Exploration Class Missions" because he was interested in learning about the medical concerns of long duration space travel and how a CMO operates in this extreme environment.

Laura Drudi (M.D., C.M. candidate 2013) is a third year medical student at McGill University. Her interest in combining her two passions of space and medicine has led her to conduct aerospace medicine research. She will be taking a one year's leave of absence from the Faculty of Medicine and will be pursuing a Diploma of Space Studies and an MSc in Experimental Surgery prior to completing her MD. She hopes to work for the manned space program as a flight surgeon and to further continue her research in space life sciences.

CROSSROADS

\title{
Ultrasound: From Earth to Space
}

\author{
Jennifer Law*, Paul. B. Macbeth
}

\begin{abstract}
Ultrasonography is a versatile imaging modality that offers many advantages over radiography, computed tomography, and magnetic resonance imagvantages over radiography, computed tomography, and magnetic resonance inagcine including diagnosis of medical and surgical diseases, management of obstetric and gynecologic conditions, assessment of critically ill patients, and procedura guidance. Advances in telecommunications have enabled remotely-guided ultraso-
nography for both geographically isolated populations and astronauts aboard the International Space Station. While ultrasound has traditionally been used in spaceflight to study anatomical and physiological adaptations to microgravity and evaluate countermeasures, recent years have seen a growth of applications adapted from terrestrial techniques. Terrestrial, remote, and space applications for ultrasound are reviewed in this pape
\end{abstract}

Keywords: Ultrasound, Spaceflight, Telemedicine, Telesonography, Remote consultation

INTRODUCTION

The use of ultrasound to diagnose and facilitate therapeutic interventions has become routine in many areas of medicine and surgery (1). With advances in computing power and probe design, ultrasound systems have become a widely available imaging modality. Traditionally, ultrasound is best known for its assessment of pregnancy and fetal growth. A growing number of applications have developed to include detailed assessments of almost every organ system. Clinicians have also identified benefits in trauma, critical care, and remote diagnostics. Ultrasound is an ideal diagnostic tool as it is noninvasive, low-cost, and highly portable. Image gependent As a result ultrasound has traditionally been limited to expert users. With new advances in ultrasound technology and personnel training the use of ultrasound has expanded beyond these traditional boundaries and has become an extension of the physical examination to many Bedside ultrasound assessments have enhanced physicians' capabilities ${ }^{*}$ To whom correspondence should be addressed

${ }^{*}$ To whom correspon University of Texas Medical Branch Division of Aerospace Medicine to accurately diagnose and understand patient physiology with the benefit of real-time feedback (2). this review we discuss the development of ultrasound technology and its expanded assessment of patients. A detailed description of its applications will be highlighted with discussion of its remote capabilities and utility for human space exploration.

\section{BACKGROUND}

History of ultrasound. The origins of ultrasonography can be traced back as far as the early 1800s, when Swiss physicist Jean-Daniel Colladon accurately determined the speed of sound through ware. In the late 1800s, Pine Curie and Jacques and pressure in crystiline materias now known as the presele in ceffect. This breakthrough low to the creation of the modern ultrasound transducer. It was not until the late 1930s when Austrian psychiatrist Dr. Karl Dussik demonstrated the clinical utility of ultrasound by generating images of brain tumors. A decade later, Dr. George Luwig characterized the differences of sound waves in different tissues. Early clinical applications primarily focused on clinical assessment of pregnancy and fetal development. As the technology matured, more clinical applications 
were identified. In the late 1970s, Europeans began using ultrasound in the assessment of critically ill trauma patients. It was nearly 15 years later when this application became more widespread in North America. Within the last two decades, ultrasound technology and technique have matured, allowing for
wide availability. New techniques and applications wide availability. New te
continue to be developed.

continue to be developed.
How ultrasound works. In contrast to How ultrasound works. In contrast to
radiography, computed tomography (CT), and magnetic resonance imaging (MRI), the acquisition and interpretation of ultrasound images are interconnected, as the ultrasonographer must be able to identify important structures and pathologies while scanning. As such, ultrasonographers require an understanding of the basic physical principles generation relies on the inter, ultrasond inage waves with differenttissues. Ultrasonography is based on the piezoelectric effect where quartz crystals are electrically stimulated, causing the crystals to change shape and produce sound waves. Conversely, when reflected sound waves hit the crystals, they produce electrical signals, which are used in combination electrical signals, which are used in combination impedance differences between different tissues. These tissue interfaces result in the reflection of transmitted ultrasound waves, creating an echo. Many of the objects seen in ultrasound images are due to the physical properties of ultrasonic beams, such as reflection, refraction, and attenuation. The ultrasound computer measures the time to detect the reflected wave, then calculates the distance to the reflected surface. These signals and calculations are then combined to generate a two-dimensional real-time image on the screen. In a typical ultrasound, millions of pulses and echoes are sent and received each second. A probe is positioned on the surface of the body and moved to oblain various views. Ultrasound waves pass easily through fluids and soft tissues, however they are unable to penetrate bone or gas. regions surrounded by bone, or ase for examing ges or air. Despit this, ultrasound has been used to examine most parts of the body. Understanding these interactions is important for establishing a clinical diagnosis.

\section{TERRESTRIAL APPLICATIONS}

Ultrasound is an essential tool for diagnostics and interventional procedures and has been used to patient populations and specialties.
Trauma. The Focused Assessment with Sonography for Trauma (FAST), originally described in 1999 by consensus definition, is used to rapidly evaluate patients with blunt or penetrating thoracoabdominal trauma (3). The FAST examination is based on evaluation of dependent portions of the peritoneal cavity-the splenorenal, hepatorenal, and rectovesical/rectovaginal recesses-for evidence of free fluid (as illustrated in Figure 1) and the pericardium for evidence of pericardial effusion or tamponade. The purpose of this assessment is to extend the physical examination to rapidly identify diagnoses that equire emergent interventions such as laparotomy or pericardiocentesis. In the setting of an unstable patient, the use of ultrasound for rapid diagnostic modalitis. The FAST North America and has examination is widely used in emergency medicine and surgical trainees. Recently this evaluation technique has been expanded to include examination of the pleural surfaces to assess for the presence of fluid (hemothorax) and air (pneumothorax). This technique is referred to as the extended FAST (EFAST) originally described by Kirkpatrick, et al $(4,5)$. Other descriptions of using ultrasound in assessment of trauma patients include identification of intraperitoneal free air (6) and pulmonary contusion (7), assessment of elevated intracranial pressures by sonographic characterization of the optic sheath (8), identification of a ruptured globe (9), and diagnosis of maxillofacial fractures (10). Despite these advances in application and technique, further development is ongoing (11-18).

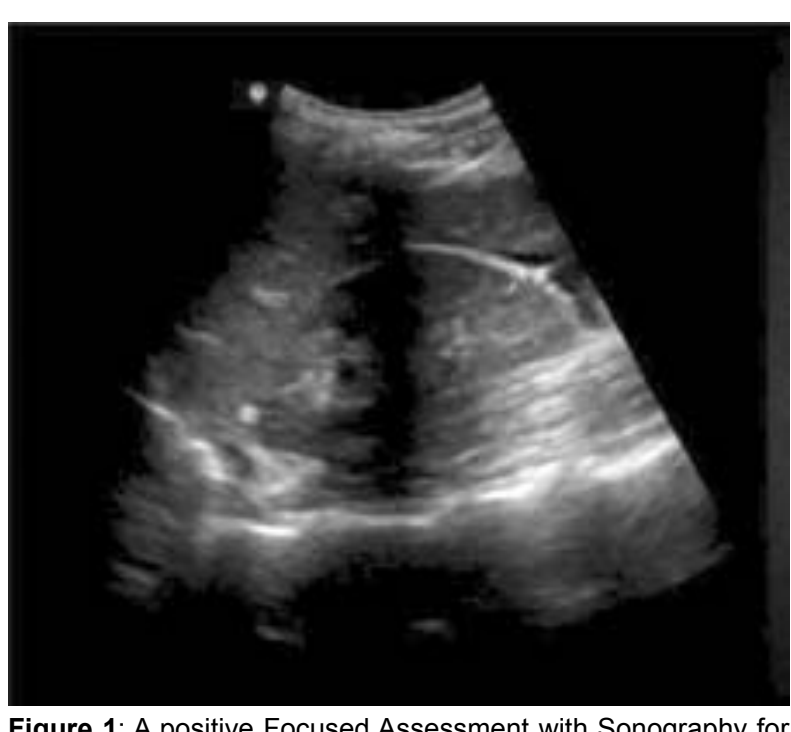
Figure 1: A positive Focused Assessment with Sonography for Truuma (FAST) examination. Ultrasound image demonstrating
a small amount of free fluid adjacent to the liver in Morrison's
Medical and surgical applications. Ultrasound is increasingly being used in the emergency department for medical resuscitations. Various protocols have been described to evaluate the undifferentiated hypotensive patient, generally involving sonographic windows of the abdomen, heart, abdominal aorta, inferior vena cava, and pleura (19-21). In less emergent settings, comprehensive transthoracic or transesophageal echocardiograms are used to evaluate the anatomical structure and functioning of the heart, yielding information including valve integrity, ejection fraction, and disease states such as endocarditis, hypertrophic cardiomyopathy, and pericardial effusion. Other applications for ultrasound include diagnosis of arterial and venous and cholis, apsenditis, hydronephris, testicular torsion, and soft tissue infections.

Obstetric and gynecological applications. Ultrasound, which does not expose patients to ionizing radiation, has traditionally been the modally of choice for the confirmation of intrauterine pregnancy, monitoring of fetal growth, and evaluation
of pregnancy-related complications including placenta of pregnancy-related complications including placenta
previa and abruption. Ultrasound also enables excellent visualization of the uterus and adnexa to diagnose such conditions as uterine fibroids, ovarian cysts, and ovarian torsion.

Procedural guidance. The application of ultrasound in interventional procedures has seen significant growth. Its use has become an established component of interventional procedures to assist physicians in the safer delivery of invasive procedures such as central venous access, arterial lines, chest tube placements, percutaneous fluid drainage including thoracentesis and paracentesis, abscess identification and drainage, and regional nerve blocks $(1,22)$. The use of ultrasound for central line placements has reduced procedure-related complications and is now considered standard of practice in many instifutions (23). Uitrasound ha a po beifoction to signilicanty difficult peripheral vascur access in the emery department $(24,25)$. Ultrasound guing reduction is currently under investigation (26). Demonstration of remote guidance of interventional procedures has been described and is presented further in the next section.

\section{REMOTE ULTRASOUND}

Ultrasonography is inherently well suited for remote application with transmission of signals for expert interpretation. The development of remote ultrasound capabilities has expanded beyond terrestrial based activities to include applications human spaceffight on the International Space talion (ISS). The benefits to patients on Earth are delivery of diagnostic and interventional capabilities in geographically isolated sites, where experts are not always avalable or there is a need for second opinion when diagnosis is difficult. In many remote localions, ultrasound may exist as the only potential

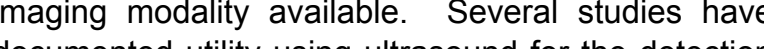
dection isolated areas where and acute medical problems in (27). (27). Recent literature suggests that und

Ground-based. Geographically isolated patients often have limited access to health care lesck of access has resulted in programs to provide elesonography to remote communities. The portability and low cost of ultrasound equipment make it ideal for this application. Global telecommunication networks, using ISDN (ground based) or D or V SAT (satellite) protocols, allow transmission of communications signals between almost any two points on Earth. These established global networks enable transmission of ultrasound images for interpretation by a remotely located expert (29)

Existing telesonography programs have focused mainly towards diagnosis of chronic or subacute medical conditions and follow-up assessments (30-33). Applications in remote areas of Australia and Canada have demonstrated its use for assessment of pregnancy and fetal health $(34,35)$. Recent advances have allowed for remote diagnostic and intervention guidance in critically ill patients $(36,37)$. A program based in Calgary, Alberta, has created a telemedicine Ink between a remote resuscilating hospital and the in the may departion two-way video conferencing and one-way ultrasound transmission, the receiving physicians alt asound mentor the remote clinician through the assessment of a trauma patient. These technologies have also been described in providing diagnostic capabilities in the battlefield.

NEEMO. Remote ultrasound has been evaluated and tested aboard Aquarius, an underwater habitat off the Florida Keys, as part of the NASA Extreme Environment Mission Operations (NEEMO). 
the role of ultrasound examination of the abdominal organs and structures. Ultrasound-trained and untrained aquanaut crewmembers conducted a series of diagnostic and interventional procedures under remote guidance from experts over $3,000 \mathrm{~km}$ away (38). Researchers demonstrated that mean efficiencies were slightly higher with

than with the use of a procedure manual.
Robotic-guided ultrasound . The capabilities of ultrasound using an audio/video link with a remote expert have also been augmented with robotic control and guidance of the ultrasound probe. Several groups are working on the development of master-slave type remote ultrasound diagnostic systems (39-41). These systems, based on a communications link between two robotic systems, allow the expert ultrasonographer The motion of a master manipulator is controllod by the expert and is reproduced by a slave manipulator carrying an ultrasound probe. Haptic technologies have also been developed and integrated into these systems to remotely provide the expert with tactile feedback. Currently these systems are prohibitively expensive and used primarily on a research basis.

\section{SPACE APPLICATIONS}

Ultrasound is currently the only medical imaging method available aboard the ISS, which hosts an ultrasound system in its Human Research Facility (HRF) that is capable of high-definition sonographic imaging for cardiac, vascular, general/ abdominal, thoracic, musculoskeletal, and other ultrasound applications, with remote guidance from experts in the Mission Control Center (MCC) (42).
While to date ultrasound has been primarily used to characterize anatomical or physiological changes in microgravity and evaluate countermeasures (43), terrestrial applications for ultrasound are increasingly being adapted for spaceflight, for diagnostic purposes. In microgravity, organs may shift position and free fluid does not pool in dependent areas, so many Parabolic flight offers the opportunity to refine adapted techniques before they are used in space.

Cardiovascular. Prolonged exposure to microgravity can result in cardiac deconditioning and orthostatic intolerance upon return to Earth due to fluid shift and loss. The first ultrasound system in space, Argument was flown on Salyut 6 and 7 to study chamber sizes and left ventricular systolic function. More advanced systems, ranging from the American Flight Echograph to the HRF Ultrasound System (HRF US), have subsequently enabled more complete evaluation of the heart in flight. On ISS Expedition 7, a study demonstrated the feasibility of coupling the HRF US to the cycle ergometer to perform stress echocardiography (42). To measure fuid shift, systems such as the French Compac Doppler System have been used to evaluate cerebra and femoral blood flow before flight, during reentry and landing, and post-flight (43).

Musculoskeletal. Many musculoskeletal complaints such as back pain, contusion, and strain are common among space crews. Ultrasound has demonstrated that the intervertebral distance between 1 and $L 5$ increases significantly in microgravity (44), which may be one of the contributing factors to back pain in space. Ultrasound can theoretically be used specific protocol for sonographic evaluation of the specific protocol for sonographic evaluation of the and the biceps and supraspinatus tendons was demonstrated by the Expedition 9 crew (45).

Trauma. Blunt and penetrating traum can occur when astronauts engage in tasks such as extravehicular activity, habitat construction, and vehicle operations. The FAST examination has been evaluated both in parabolic flight and aboard the ISS. In the former case, fluid was introduced to the peritoneal cavity of restrained porcine models and it was found that fluid in the subhepatic space was the most sensitive in microgravity (46). In the latter case, a crewmember was able to perform the exam on herself without difficulty (47). Sonographic diagnosis of pneumothorax, hemothorax (48) and ultrasoundguided percutaneous aspiration of intraperitoneal fluid to treat peritonitis (49) have also been demonstrated

Genitourinary. Urinary tract infections,
m porcine models in parabolic flight. urosepsis, urinary retention, and nephrolithiasis have all occurred in past space flights. The HRF US has been used to conduct renal and bladder surveys for evaluation of the renal anatomy, vascular flow and ureteral patency $(50,51)$. Ultrasound-guided urinary obstruction was demonstrated in porcine models in parabolic flight which can be adapted to space in case luminal catheterization is not posible (52).

Ocular. Ocular foreign bodies are a common problem in microgravity, where small particles float
freely, sometimes undetected. During the Shuttle-Mir Program, there was also an incidence of blunt traum to the orbit when a bungee cord restraint system broke (53). Recently, a non-physician crewmember was able to use the HRF US to perform a comprehensive ocular examination on himself with remote guidance
from the MCC, visualizing the anatomical structures of the globe, iris, and pupil (54)

Sinuses. Astronauts in space are predisposed to sinusitis due to cephalad fluid shift and altered drainage of the sinuses in microgravity; superinfection of the sinuses may result in acute bacterial rhinosinusitis. Beninnger et al. introduced fluid to porcine sinuses in parabolic flight and found that in microgravity, fluid could be visualized on ultrasound as a 2 to $3 \mathrm{~mm}$ thick air-fluid interface distributed along the entire sinus cavity. The authors further noted that ultrasound-guided sinus drainage procedures were possible (55)

Decompression sickness. Space crews are susceplble to decompression sickness (DCS) when they transition from one environment to a more (EVA) suit. When the aubient presure nitrogen dissolved in the bloodstream comes out of solution and forms bubbles, which may circulate in the sody or at traped, causing local symptoms. Nitroge body orgetrapped, causing local symptoms. Nitrogen in-suit system has been recommended by the NASA Medical Operations EVA Integrated Product Team to better understand bubble formation and arterialization in flight to quantify the risk of DCS (56).

Future applications. For future Exploration Class missions, astronauts will require autonomous medical capabilities given communication delays between the crew and medical support staff on the ground; real-time remote guidance will likely be replaced by one or more trained physicianastronauts onboard. Timely evacuation to Earth will not be possible. Thus, ultrasound will play a greater role in the medical armamentarium for diagnosis and treatment of medical contingencies in space. Sargsyan et al. (42) has catalogued an extensive list of ultrasound applications that have been tested in microgravity and/or with remote guidance, as well as those that are potentially feasible in space. In addition to the previously deschibed applicalions, more novel periapical abscesses, thyroiditis, and retroperitoneal hematoma. Finally low-intensity ultrasound has been suggested to promote bone formation in vitro (57) and suggested to proy low-he be microgravity-induced osteopenia.

\section{CONCLUSION}

Ultrasound is a well-proven diagnostic in space. Its versatility, portability, noninvasiveness, lack of ionizing radiation, and tele-transmittability make ultrasound an ideal imaging method for space crews. Although ultrasound does not provide the same resolution for evaluating gas-filled or osseous structures as CT or MRI, the role of ultrasound continues to expand, both on Earth and in space. New applications being investigated for spaceflight may be adapted for use on Earth, especially in remote environments that do not have ready access to advanced imaging modalities or expert radiologists and vice versa. Indeed, ultrasound shows much fitting both astronauts and patients on promise

\section{REFERENCES}

Kirkpatrick AW, Šustic A, Blaivas M. Introduction to the 2007;35(5):S123-5.

Satava RM: Disruptive visions: A robot is not a machine. systems integration for surgeons. Surg Endosc. 2004 Apr 18(4):617-20.

Scalea TM, Rodriguez A, Chiu WC, Brenneman FD, Fallon WF Jr, Kato K, et al. Focused Assessment with Sonography for Trauma (FAST): results from an international conKirkpatrick AW, Sirois M. L. 1999 Mar;46(3):466-72. Ball $\mathrm{CG}$, et al. Hand-held thoracic KB, Liu D, Rowan $\mathrm{K}$, post-traumatic pneumothoraces: the Extended Focused Assessment with Sonography for Trauma (EFAST). J Trauma. 2004 Aug;57(2):288-95

. Blaivas M, Lyon M, Duggal S. A prospective comparison of supine chest radiography and bedside ultrasound for the diagnosis of traumatic pneumothorax. Acad Emerg Med. 2005;12:844-9.

Blaivas M, Kirkpatrick AW, Rodriguez-Galvez M, Ball CG. Sonographic depiction of intraperitoneal free air. $J$ Trauma 2009 Sep; $67(3): 675$

Stone MB, Secko MA. Bedside ultrasound diagnosis of pulmonary contusion. Pediatr Emerg Care. 2009 Dec;25(12):854-5

Soldatos T, Chatzimichail K, Papathanasiou M, Gouliamo A. Optic nerve sonography: a new window for the nonEmerg Med J. 2009 Sep;26(9):630-4.

Ladner H, Ting V, Radeos MS, Samudre $S$. The utility of bedside ultrasound in the de tion of a ruptured globe in a porcine model. West $J$ Emerg Med. 2009 Nov;10(4):263-6.

10. Blazic RJ, Wolf S, Hamilton DR, Sargsyan AE, Melton SL, Diebel LN, et al. Rapid ultrasound diagnosis of maxillofacial injury [abstract]. Aviat Space Environ Med. 2003 Apr;74(4):438-9. 
11. Boulanger BR, McLellan BA, Brenneman FD, Ochoa J, Kirkpatrick AW. Prospective evidence of the superiority of a sonography-based algorithm in the assessment of blunt abdominal injury. J Trauma. 1999 Oct;:47(4):632-7.

12. Rozycki GS, Ochsner MG, Jaffin JH, Champion HR. Prospective evaluation of surgeon's use of ultrasound in the evaluation of trauma patients. J Trauma 1993;34:516-26.

13. Healey MA, Simons RK, Winchell RJ, Gosink BB, Casola $G$, Steele JT, et al. A prospective evaluation of abdominal ultrasound in blunt trauma: is it useful? J Trauma. 1996 Jun;40(6):875-83; discussion 883-5.

14. Rozycki GS, Ballard RB, Feliciano DV, Schmidt JA, Pennington SD. Surgeon-performed ultrasound for the assessment of truncal injuries: lessons learned from 1540 patients. Ann Surg. 1998 Oct;228(4):557-67.

15. Boulanger BR, Kearney PA, Tsuei B, Ochoa JB. The rouine use of sonography in penetrat

16 UdobiKF Rodriguez A Chiu WC Scalea TM Role of utra Uob KF, Rodnguz A, Chiu WC, Scalea TM. Role of ultrsonography in penefrating abdominal trauma: a pros
tive clinical study. J Trauma. 2001 Mar; $50(3): 475-9$.

17. Kirkpatrick AW, Simons RK, Brown DR, Ng AK, Nicolaou S. Digital hand-held sonography utilised for the focused assessment with sonography for trauma: a pilot susedy. AnAcad Med Singapore. 2001 Nov; 30(6):577-81.

18. Kirkpatrick AW, Simons RK, Brown R, Nicolaou S, Dulchavsky S. The hand-held FAST: experience with handheld trauma sonography in a level-I urban trauma center. Injury. 2002 May;33(4):303-8.

19. Rose JS, Bair AE, Mandavia D, Kinser DJ. The UHP ultrasound protocol: a novel ultrasound approach to the empirc evaluation of the undifferentiated hypotensive patient. Am J Emerg Med. 2001 Jul; 19(4):299-302.

20. Atkinson PR, McAuley DJ, Kendall RJ, Abeyakoon O, Reid CG, Connolly J, et al. Abdominal and Cardiac Evalua tion with Sonography in Shock (ACES): an approach by emergency physicians for the use of ultrasound in patients with undifferentiated hypotension. Emerg Med J. 2009 Feb;26(2):87-91.

21. Perera P, Mailhot T, Riley D, Mandavia D. The RUSH exam: Rapid Ultrasound in SHock in the evaluation of the critically iil. Emerg Med Clin North Am. $2010 \mathrm{Feb}, 28(1): 29-56$, vii.

22. American College of Emergency Physicians. Emergency
ultrasound guidelines [policy statement]. Dallas (TX): ultrasound güd

23. Kumar A, Chuan A. Ultrasound guided vascular access: efficacy and safty. Best Pract Res Clin Anaesthesiol. 2009 ficacy and safety. Best Pract Res Clin Anaesthesiol. 2009
Sep;23(3):299-311. 24. Bauman $M$, Braude $D$, Crandall $C$. Ultrasound-guidance vs standard technique in difficult vascular access patients by 25. Dargin JM, Rebholz CM, Lowenstein RA, Mitchell PM Feldman JA. Ultrasonography-guided peripheral intrave- nous catheter survival in ED patients with difficult access. Am J Emerg Med. 2010 Jan;28(1):1-7.

26. Chinnock B, Khaletskiy A, Kuo K, Hendey GW. Ultrasoundguided Reduction of Distal Radius Fractures. J Emerg Med. 2009 Dec 1. [Epub ahead of print]

27. Shuster M, Abu-Laban RB, Boyd J, Gauthier C, Mergler $\mathrm{S}$, Shepherd $\mathrm{L}$, et al. Focused abdominal ultrasound for blunt trauma in an emergency deparment without advanced imaging or on-site surgical capability. CJEM. 2004 Nov;6(6):408-15

28. Shackford SR, Rogers FB, Osler TM, Trabulsy ME, Claus DW, Vane DW. Focused abdominal sonogram for trauma the learning curve of nonradiologist clinicians in detecting hemoperitoneum. J Trauma. 1999 Apr;46(4):553-62; discussion $562-4$

29. Chan FY, Soong B, Watson D, Whitehall J. Realtime feta ultrasound by telemedicine in Queensland. A successt

0. Tachakra S, Uko Uche C, Stinson A. Four years'

ence of telemedicine support of a $\mathrm{A}$. Four years' exper ment service J Telemed Tolocar. 2002:8 Suppl 2:87-9.

1. Beach M. Goodall L Miller P. Evaluating telemedicine for minor injuries units. $J$ Telemed Telecare. 2000:6 Supp 1:S90-2.

32. Salmon S, Brint G, Marshall D, Bradley A. Telemedicine use in two nurse-led minor injuries units. $J$ Telemed Telecare. 2000;6 Suppl 1:S43-5.

33. Tachakra S, Dutton D, Newson R, Hayes J, Sivakumar A Jaye $P$, et al. How do teleconsultations for remote trauma management change over a period of time? J Telemed Telecare. 2000;6 Suppl 1:S12-5.

34. Duchesne JC, Kyle A, Simmons J, Islam S, Schmieg RE Jr, Olivier J, et al. Impact of telemedicine upon rural traum care. J Trauma. 2008 Jan;64(1):92-7; discussion 97-8.

5. Tachakra S, Jaye P, Bak J, Hayes J, Sivakumar A. Supervising trauma life support by telemedicine. J Teleme Telecare. 2000;6 Suppl 1:S7-11.

6mith P, Brebner E. Tele-ultrasound for remote areas. Telemed Telecare. 2002;8 Suppl 2:80-1.

3. Wootton R, Mckelvey A, McNicholl B, Loane M, Hore D Howarth P, et al. Transfer of telemedical support to Cornwall from a national telemedicine network during a

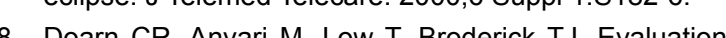

Devaluation of

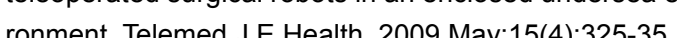

Courreges $F$ Vieyres P, Istepanian RS, A belle P, Bru C Clinical trials and evaluation of a mobile, robotic teleutra sound system. J Telemed Telecare. 2005:11 Supp 1:46-9.

40. Courrèges F, Al Bassit L, Novales $C$, Rosenberger $C$, SmithGuerin N, Brù C, Gilabert R, Vannoni M, Poisson G, Vieyres P. A tele-operated mobile ultrasound scanner using a light-weight robot. IEEE Trans Inf Technol Biomed. 2005 Mar;9(1):50-8.
41. Tateishi N, Kimura E, Ishihara K. Development of a telechography system by using an echographic diagnosis bot. Igaku Butsuri. 2003;23(1):24-9.

42. Sargsyan AE, Hamilton DR, Melton SL, Young J (Wyle Laboratories and NASA Johnson Space Center). The International Space Station ultrasound imaging capability overview for prospective users. Technical report. Houston (TX): National Aeronautics and Space Administration; 2006 Dec. Report No.: TP-2006-213731.

43. Martin DS, South DA, Garcia KM, Arbeille P. Ultrasound Med Biol. 2003 Jan;29(1):1-12.

4h. Ledsome JR. Spinal changes in microgravity. In: Snyder RS, compiler. Second International Microgravity Laboratory (IML-2) final report, NASA reference publication 1405 Huntsville (AL): NASA; 1997. p. 182-5.

. Fincke EM, Padalka G, Lee D, van Holsbeeck M, Sargsya $A E$, Hamilon $D R$, el al. Evaluation of shoulder integrity in

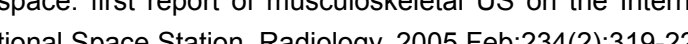

Kirkpatrick AW, Hamiton DR, Nicolaou S, Sargsyan AE,

. Sonography for Trama in wighlessess: a easibly study. J Am Coll Surg. 2003 Jun;196(6):833-44.

47. Sargsyan AE, Hamiton DR, Jones JA, Melton S, Whitson PA, Kirkpatrick AW, et al. FAST at MACH 20: clinical ultrasound aboard the International Space Station. I Trauma. 2005 Jan; $58(1): 35-9$

48. Hamilton DR, Sargsyan AE, Kirkpatrick AW, Nicolaou S, Campbell M, Dawson DL, et al. Sonographic detection of pneumothorax and hemothorax in microgravity. Aviat Space Environ Med. 2004 Mar;75(3):272-7.

49. Kirkpatrick AW, Nicolaou S, Campbell MR, Sargsyan AE, Dulchavsky SA, Melton S, et al. Percutaneous aspiration of fluid for management of peritonitis in space. Aviat Space Environ Med. $2002 \mathrm{Sep} ; 73(9): 925-30$

Jennifer Law (M.D.) is an aerospace medicine resident and the 2011-2012 chief resident of aerospace medicine at the University of Texas Medical Branch (UTMB) in Galveston, Texas. She received her Bachelor of Science degree in electrical engineering from the Massachusetts Institute of Technology and Med-

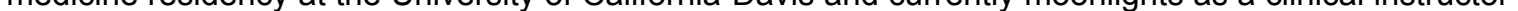
the emergency dep a Laboratory on the Mars Exploration Rovers project and supported pre-launch operalions at the Kennedy medicine, and trauma.

Paul McBeth (MASc, MD) is currently a General Surgery residency at the University of Calgary, where earlier he had earned robotics and human factors. He served as a Robotics Research Engineer where he assisted in the design and development of a MR compatible, image-guided neurosurgical robot system. Dr. McBeth is also

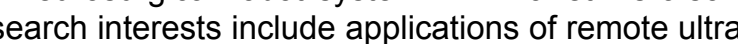

Jones J, Sargsyan AE, Melton SL, Martin D, Hamilton DR. Development of imaging protocols for in-flight screening for [abstract]. Aviat Space Environ Med. 2003 Apr;74(4):439. Dulchavsky SA, et al. Diagnostic ultrasound at MACH 20 . Med Biol. 2009 Jul;35(7):1059-67.

Campes Kirkpatrick AW, Hamilton DR, Sargsyan AE, terization in microgravity. Can J Urol. 2007 Appr14(2):3493Gontcharov IB, Kovachevich IV, Pool SL, Navinkov OL, in the NASA ogomolov $W$, et al. In-fight medical incidents Jul; $76(7): 692-6$.

DR, MCFalli K Duchavsky SA AE, Melton S, Hamilton trauma; clinical ultrasound aboard the International Space

Benninger MS, McFarlin K, Hamilton DR, Rubinfeld I, Sargfluid levels in swine et al. Ultrasound evaluation of sinus Space Environ Med. 2009 Dec;80(12):1063-5.

Extravehicular Activity Integrated Prod Houston (TX): National Aeronautics and intensity ultrasound stimulation on a model of osteoclastic precursor. Acta Astron. 2007;60:383-90. 